\title{
PET Changes Management and Improves Prognostic Stratification in Patients with Recurrent Colorectal Cancer: Results of a Multicenter Prospective Study
}

Andrew M. Scott ${ }^{1,2}$, Dishan H. Gunawardana ${ }^{1}$, Ben Kelley ${ }^{3}$, John G. Stuckey ${ }^{4}$, Amanda J. Byrne ${ }^{1}$, Jayne E. Ramshaw ${ }^{5}$, and Michael J. Fulham ${ }^{6}$

${ }^{I}$ Centre for PET, Austin Hospital, Melbourne, Australia; ${ }^{2}$ Ludwig Institute for Cancer Research, Austin Hospital, Victoria, Australia; ${ }^{3}$ Southern X-Ray Clinics, Wesley Hospital, Brisbane, Australia; ${ }^{4}$ MIA, Monash Medical Centre-Moorabbin Campus, Melbourne, Australia; ${ }^{5}$ Australian and New Zealand Association of Physicians in Nuclear Medicine, Melbourne, Australia; and ${ }^{6}$ Department of PET and Nuclear Medicine, Royal Prince Alfred Hospital, and Faculty of Medicine and School of Information Technologies, University of Sydney, Sydney, Australia

The aims of our study were to examine the impact of PET in changing management in patients with proven or suspected colorectal cancer recurrence and to assess the impact of management change on disease-free survival. Methods: Symptomatic patients with a residual structural lesion suggestive of recurrent tumor (group A) or patients with pulmonary or hepatic metastases considered to be potentially resectable (group B) underwent PET scans. Pre-PET management plans were documented by referring clinicians unaware of the PET results, and follow-up to 12 mo was performed to determine actual management and clinical outcomes. Results: A total of 191 patients (118 men and 73 women; mean age, $66 \mathrm{y}$ ) were studied. PET detected additional sites of disease in $48.4 \%$ of patients in group $A$ and in $43.9 \%$ of patients in group $B$. A change in planned management was documented in $65.6 \%$ of group A and in $49.0 \%$ of group B patients. These management plans were implemented in $96 \%$ of patients. Follow-up data in group A showed progressive disease in $60.5 \%$ of patients with additional lesions detected by PET, compared with conventional imaging, and in $36.2 \%$ of patients with no additional lesions detected by PET $(P=0.04)$. In group $B$, progressive disease was identified in $65.9 \%$ of patients with additional lesions detected by PET and in $39.2 \%$ of patients with no additional lesions detected by PET $(P=0.01)$. PET also provided valuable prognostic information on patients stratified into curative- or palliative-intent groups. Conclusion: These data demonstrate the significant impact of PET on management and outcomes in patients with suspected recurrent colorectal cancer.

Key Words: molecular imaging; oncology; PET/CT; PET; colorectal cancer; management change

J Nucl Med 2008; 49:1451-1457

DOI: 10.2967/jnumed.108.051615

Received Feb. 10, 2008; revision accepted May 28, 2008

For correspondence or reprints contact: Andrew M. Scott, Centre for PET, Austin Hospital, Studley Rd., Heidelberg, Victoria 3084, Australia.

E-mail: andrew.scott@ludwig.edu.au

COPYRIGHT @ 2008 by the Society of Nuclear Medicine, Inc.

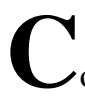

olorectal cancer is the second most common cancer, after skin cancer, in Australia (1). It was estimated to be the fourth most common cancer in the United States in 2006 (2). Surgery will cure approximately $50 \%$ of patients; however, in $30 \%-40 \%$ of patients with stage II or III colorectal cancer, recurrent disease or a second colorectal primary will develop (3). A large proportion of recurrences will be localized to a single organ, such as the liver, or an anatomic region, such as the pelvis $(4,5)$. Some patients with localized recurrence will be cured with further surgery, and Goldberg et al. reported a 23\% 5-y disease-free survival (5). Tepper et al., in another large series, showed that surgery for single-site recurrence resulted in a 27\% 5-y disease-free survival (4). There is no clear consensus on the factors that predict the success of surgery for recurrent hepatic and pulmonary metastases (6-9). However, for patients with recurrence localized to the liver, there is general agreement that multiple hepatic metastases and the presence of extrahepatic lesions confer an adverse prognosis.

${ }^{18}$ F-FDG PET has been shown to be highly accurate in the detection of recurrent and metastatic colorectal cancer (1015). A PET scan has comparable sensitivity to a CT scan for the detection of colorectal liver metastases (12-14) but has superior sensitivity in the detection of extrahepatic disease, compared with CT, and changes the estimation of disease extent in over one third of patients $(11,13,16)$. Several reports also indicate that PET can influence the management of patients with metastatic colorectal cancer $(11,17-20)$, but there are few prospective studies $(11,17)$. Further, multicenter studies with large patient groups have not been performed, and the impact of PET on patient outcomes (progression-free survival) has not been previously reported.

Our aims in this prospective multicenter study were to evaluate PET in patients with suspected and proven recurrent 
colorectal cancer undergoing: (a) characterization of residual structural lesion after initial therapy, and (b) preoperative staging before resection of apparently isolated metastases. The PET findings were compared with the findings from conventional imaging, and the impact of PET on patient management was determined. We also evaluated the effect that these management changes had on progression-free survival.

\section{MATERIALS AND METHODS}

\section{Patients}

This prospective study was conducted at four Australian PET centers. Eligible patients had a previous diagnosis of colorectal cancer proven by histology and either a symptomatic residual structural lesion (i.e., on CT, ultrasound, or MRI) with appearances equivocal for recurrent tumor (group A patients) or pulmonary or hepatic metastases that were potentially resectable as determined by conventional imaging (group B patients). Patients had to be suitable for active treatment if localized disease was confirmed and at least $18 \mathrm{y}$ old. Patients were excluded if they had received chemotherapy completed less than 1 wk before the PET examination, had abdominal surgery within 6 wk of the PET examination, had uncontrolled diabetes mellitus, or were pregnant at the time of the PET scan. The institutional ethics review boards at the participating hospitals approved the study, and informed consent was obtained from all patients.

\section{Conventional Staging Investigations}

All patients had contrast-enhanced CT scans of the chest and/or abdomen and pelvis performed within $6 \mathrm{wk}$ of their PET scans. Other imaging modalities were used according to clinical indication. Investigators were required to record whether lesions seen on PET were adequately assessed by prior anatomic imaging methods.

\section{PET Scan Procedure and Image Interpretation}

Patients fasted for a minimum of $6 \mathrm{~h}$ before the PET study. At the discretion of the physician reporting the PET study, urinary catheters were inserted before the PET scan to optimize pelvic imaging. ${ }^{18} \mathrm{~F}-\mathrm{FDG}$ (120-400 MBq) was administered intravenously. After a minimum uptake period of $45 \mathrm{~min}$. PET emission data were acquired from the base of skull to the upper thighs. At institutions with PET/CT scanners, CT scans were performed for anatomic localization and attenuation correction of image data. PET transmission data were used for attenuation correction if the CT data were not available. PET scans were interpreted by experienced, credentialed PET specialists with full knowledge of conventional imaging results; all sites of lesions and their concordance or discordance with other data were recorded. Comparison of pre-PET results with findings of PET scans was performed. Validation of PET scan results for tumor detection, compared with conventional staging results, was performed by evaluating these results with any subsequent operative, pathologic, and imaging findings at 6 mo after the PET scan in all patients.

\section{Documentation of Management Plans}

The referring clinicians were required to document a management plan for the patient before they received the results of the PET scans but with access to results from all other clinical and conventional imaging. This management plan outlined the modalities planned, such as surgery, chemotherapy, radiotherapy, or a combination of these modalities. Information was also collected on the planned extent of these therapies. Following the release of the PET results, a second management plan was recorded, including any changes in intended management as a result of the PET scan. The actual management plan, based on follow-up, was also recorded.

\section{Impact of PET on Patient Management}

The impact of PET on patient management plans was assessed by comparing pre-PET management plans with post-PET management plans for individual patients, and by asking the referring clinician if the management had been changed on the basis of the PET results. Referring clinicians were also asked to assess the impact of PET on management as follows: None (PET result indicates that a management different from the one planned may be appropriate, but no change in management occurs as a result of PET information, allowing for management decisions that may be made for other clinical reasons); Low (PET result is consistent with planned management, and treatment modality or intent is unchanged); Medium (the treatment modality or intent remains unchanged, although the planned procedure, dose of therapy, or mode of delivery is altered because of PET result); and High (the treatment modality or intent is changed because of PET result).

\section{Patient Follow-up and Prediction of Disease-Free Survival on Basis of PET}

Patients underwent follow-up for 12 mo after the PET scan. The date of tumor progression as determined by the treating clinician was recorded. The detection of additional lesions by PET, when compared with conventional imaging, was analyzed for prediction of progression-free survival for individual patients. The impact of stratification of patients into curative- versus palliative-intent groups on the basis of PET results, and into surgical-intent groups, on progression-free survival was also analyzed.

\section{Statistics}

A sample size of at least 100 patients in total was initially planned based on the assumption that if 20 patients had data insufficient for analysis, and if $20 \%$ of the remaining patients were to have a change in management plan, the $95 \%$ confidence intervals (CIs) would be $11 \%-29 \%$. Groups A and B were also analyzed separately, and power calculation remained valid for each of these groups, as more than 80 patients were evaluable in each of the groups. Bivariate tables were analyzed using the $\chi^{2}$ test. Survival analyses were performed using the Kaplan-Meier method, and the groups were compared using the log-rank test.

\section{RESULTS}

\section{Patient Demographics}

Between November 23rd, 2003, and August 12th, 2004, 204 patients were enrolled in the study. Thirteen patients were ineligible for data analysis, as the treatment plans for these patients were not initiated before patient death or it was not possible to confirm that the treatment plan had been initiated, leaving 191 eligible patients (Royal Prince Alfred Hospital in Sydney, $n=122$; Austin Hospital in Melbourne, $n=27$; MIA Moorabbin in Melbourne, $n=26$; and Wesley Hospital in Brisbane, $n=16$ ). Group A consisted of 93 patients (patients with lesions equivocal for recurrent tumor). The median age was 66 y (range, 26-85), and 58\% were men. For group A, the suspected lesions seen on pre-PET evaluation are shown in Table 1. Group B consisted of 98 patients (patients with po- 
TABLE 1

Sites of Lesions Identified by Pre-PET Evaluation and by PET for Group A Patients

\begin{tabular}{lrc}
\hline \multicolumn{1}{c}{ Site } & Pre-PET & PET \\
\hline Liver & 43 & 43 \\
\hline Pelvis & 33 & 41 \\
Lung & 32 & 33 \\
Retroperitoneum & 15 & 17 \\
Mesentery & 14 & 15 \\
Bone & 5 & 12 \\
Bowel & 8 & 12 \\
Adrenal & 6 & 2 \\
Other & 11 & 26 \\
Total & 167 & 201 \\
\hline
\end{tabular}

tentially resectable liver or lung metastases). The median age was 66 y (range, 45-82), and 65\% were men.

\section{Lesions Detected by PET, Compared with Conventional Imaging}

In group A, $90(96.8 \%)$ patients underwent a PET/CT scan; PET alone was used in 3 (3.2\%). In group B, $83(84.7 \%)$ patients underwent a PET/CT scan; PET alone was used in 15 $(15.3 \%)$.

In group $\mathrm{A}$, additional sites of disease were identified in 45 of $93(48.4 \%)$ patients. The sites of lesions in group A are shown in Table 1 . In group B, additional sites of disease were identified in 43 of $98(43.9 \%)$ patients (1 patient had no lesions identified before PET or on PET). The sites of lesions in group B are shown in Supplemental Table 1 (supplemental materials are available online only at http:// jnm.snmjournals.org).

\section{Post-PET Change in Management Plan}

In group A, 61 patients $(65.6 \%)$ had management plans altered on the basis of the PET result (95\% CI, 56.0\%-75.3\%). In group B, 48 patients (49.0\%) had a change in management plan on the basis of the PET scan (95\% CI, 39.1\%-58.9\%).
The pre-PET and post-PET management plans and changes for groups A and B are shown in Tables 2 and 3.

In group A patients, referring clinicians rated the impact of PET on patient management as high in 60 (64.5\%), medium in $5(5.4 \%)$, low in $24(25.8 \%)$, and none in $4(4.3 \%)$ patients. These results were significant by $\chi^{2}$ analysis $\left(\chi^{2}=88.38\right.$, $P<0.001)$. For group B patients, the impact of PET on patient management was rated as high in $41(41.8 \%)$, medium in $5(5.1 \%)$, low in $44(44.9 \%)$, and none in 8 $(8.2 \%)$ patients. These results were significant by $\chi^{2}$ analysis $\left(\chi^{2}=53.27, P<0.001\right)$.

Referring clinicians were also asked to record if the management plan intent was curative or palliative pre-PET and if there was a change on the basis of the PET results. In group $\mathrm{A}$, the number of curative-intent patients remained similar, with 49 pre-PET and 50 post-PET; however, $29.0 \%$ of patients had treatment intent altered by PET (Table 4). For group B, the number of curative-intent patients reduced from 88 pre-PET to 69 post-PET, and $23.5 \%$ had treatment intent altered by PET results (Table 4). The changes in intent were statistically significant for group A $\left(\chi^{2}=59.29, P<0.001\right)$ and group $\mathrm{B}\left(\chi^{2}=87.82, P<0.001\right)$.

\section{Actual Treatment}

At the 6-mo follow-up, actual treatment was compared with the treatment planned post-PET. A medical oncologist with experience in the treatment of colorectal cancer reviewed the data and determined if the actual treatment was appropriate on the basis of the PET results.

For the 92 patients in group A for whom information on actual treatment was available, 57 patients received treatment as planned post-PET and 35 patients received treatment that differed from that planned post-PET. Review of the actual treatment implemented in these 35 patients showed that in 33 of the 35 cases, the actual treatment implemented was consistent overall with the PET results. In 2 patients, the treatment was not consistent; PET was false-positive in 1 patient and false-negative in another. In this second patient,

TABLE 2

Pre-PET and Post-PET Management Plans for Group A Patients

\begin{tabular}{|c|c|c|c|c|c|c|}
\hline \multirow[b]{3}{*}{ Management plan } & \multirow{2}{*}{\multicolumn{2}{|c|}{$\begin{array}{c}\text { Pre-PET } \\
\text { All patients }\end{array}$}} & \multicolumn{4}{|c|}{ Post-PET } \\
\hline & & & \multicolumn{2}{|c|}{$\begin{array}{l}\text { Management } \\
\text { unchanged }\end{array}$} & \multicolumn{2}{|c|}{$\begin{array}{l}\text { Management } \\
\text { changed }\end{array}$} \\
\hline & $n$ & $\%$ & $n$ & $\%$ & $n$ & $\%$ \\
\hline Radiotherapy & 7 & 7.5 & 3 & 3.2 & 4 & 4.3 \\
\hline $\begin{array}{l}\text { Radiotherapy and chemotherapy } \\
\text { (consecutive or concurrent) }\end{array}$ & 1 & 1.1 & 0 & 0.0 & 1 & 1.1 \\
\hline Surgery & 25 & 26.9 & 14 & 15.1 & 11 & 11.8 \\
\hline $\begin{array}{l}\text { Surgery and chemotherapy, with or without } \\
\text { radiotherapy (consecutive or concurrent) }\end{array}$ & 25 & 26.9 & 8 & 8.6 & 17 & 18.3 \\
\hline Chemotherapy & 18 & 19.4 & 3 & 3.2 & 15 & 16.1 \\
\hline $\begin{array}{l}\text { Chemotherapy with or without radiotherapy, } \\
\text { and surgery (consecutive or concurrent) }\end{array}$ & 5 & 5.4 & 1 & 1.1 & 4 & 4.3 \\
\hline Other & 12 & 12.9 & 3 & 3.2 & 9 & 9.7 \\
\hline Total & 93 & 100.0 & 32 & 34.4 & 61 & 65.5 \\
\hline
\end{tabular}


TABLE 3

Pre-PET and Post-PET Management Plans for Group B Patients

\begin{tabular}{|c|c|c|c|c|c|c|}
\hline \multirow[b]{3}{*}{ Management plan } & \multirow{2}{*}{\multicolumn{2}{|c|}{$\begin{array}{c}\text { Pre-PET } \\
\text { All patients }\end{array}$}} & \multicolumn{4}{|c|}{ Post-PET } \\
\hline & & & \multicolumn{2}{|c|}{$\begin{array}{l}\text { Management } \\
\text { unchanged }\end{array}$} & \multicolumn{2}{|c|}{$\begin{array}{l}\text { Management } \\
\text { changed }\end{array}$} \\
\hline & $n$ & $\%$ & $n$ & $\%$ & $n$ & $\%$ \\
\hline Radiotherapy & 0 & 0.0 & 0 & 0.0 & 0 & 0.0 \\
\hline Surgery & 63 & 64.3 & 37 & 37.8 & 26 & 26.5 \\
\hline $\begin{array}{l}\text { Surgery and chemotherapy, with or without radiotherapy } \\
\text { (consecutive or concurrent), or other }\end{array}$ & 14 & 14.3 & 4 & 4.1 & 10 & 10.2 \\
\hline Chemotherapy & 4 & 4.1 & 1 & 1.0 & 3 & 3.1 \\
\hline Chemotherapy and surgery (consecutive or concurrent) & 9 & 9.2 & 5 & 5.1 & 4 & 4.1 \\
\hline Other & 7 & 7.1 & 3 & 3.1 & 4 & 4.1 \\
\hline Other than chemotherapy & 1 & 1.0 & 0 & 0.0 & 1 & 1.0 \\
\hline Total & 98 & 100.0 & 50 & 51.0 & 48 & 49.0 \\
\hline
\end{tabular}

both PET and CT missed omental disease. Detailed data on these 35 cases are provided in Supplemental Table 2.

For group B, in 97 patients for whom information on actual treatment was available, there were 68 patients whose actual treatment was as planned post-PET and 29 patients whose actual treatment differed from that planned post-PET. Review of these 29 patients showed that in 24 , the actual treatment implemented was consistent overall with the PET results. PET was false-negative for lesions in 3 patients; in 2 of these, CT was also false-negative and in the third patient PET missed an adrenal lesion confirmed on subsequent CT. In 2 patients, the reasons for the differences remain unknown. Detailed data on these 29 cases are provided in Supplemental Table 3.

Thus, overall, the management plan actually implemented was consistent with the stated post-PET management plan in $96 \%$ of patients.

\section{Progression-Free Survival}

Patients with additional lesions detected on PET compared with conventional imaging had inferior progressionfree survival (Fig. 1). Follow-up data showed that in group A, progressive disease was identified in $60.5 \%$ of patients with additional lesions detected on PET compared with con-

TABLE 4

Comparison of Management Intent Before PET and After PET

\begin{tabular}{llc}
\hline \multirow{2}{*}{$\begin{array}{c}\text { Change in intent } \\
\text { of treatment }\end{array}$} & \multicolumn{2}{c}{ Proportion of patients } \\
\cline { 2 - 3 } & Group A & Group B \\
\hline $\begin{array}{l}\text { No change } \\
\text { Change from curative } \\
\text { to palliative }\end{array}$ & $13(71.0 \%)$ & $75(76.5 \%)$ \\
$\begin{array}{c}\text { Change from palliative } \\
\text { to curative }\end{array}$ & $14(15.0 \%)$ & $21(21.5 \%)$ \\
Total & $93(100.0 \%)$ & $2(2.0 \%)$ \\
\hline
\end{tabular}

ventional imaging, and $36.2 \%$ patients with no additional lesions detected by PET $(P=0.04)$. In group $\mathrm{B}$, progressive disease was identified in $65.9 \%$ of patients with additional lesions detected on PET and in $39.2 \%$ patients with no additional lesions detected on PET $(P=0.01)$. Patients in group B stratified by PET as having additional lesions localized outside the liver or lungs, compared with those with liver- or lung-only disease, also had inferior progression-free survival (Fig. 2).

Patients classified as requiring curative or palliative treatment pre- and post-PET were compared using KaplanMeier survival analyses (Fig. 3). Patients in groups A and B were better stratified into curative and palliative groups after PET than before PET on the basis of progression-free survival. In addition, group B patients planned for surgery after PET had a superior progression-free survival than those planned before PET (after PET, $P=0.03$ ) and similar survival to those patients who actually proceeded to surgery (data not shown). A total of 4 patients ( 2 in group A and 2 in group B) were excluded from the Kaplan-Meier analyses because of inadequate follow-up data.

\section{DISCUSSION}

Previous studies have shown the impact of PET on the management of cancer in general and on colorectal cancer in particular. Fernandez et al. reported that the 5-y survival of patients with potentially resectable liver metastases from colorectal cancer was $58 \%$ in a population screened with PET, as compared with $30 \%$ in previous series (21). Recently published data from the National Oncologic PET Registry in patients with a variety of cancers (particularly prostate, pancreas, and ovarian cancers) showed that intended management was changed in $36.5 \%$ of patients after PET (22). In a single-institution prospective study of colorectal cancer, management was changed as a result of PET in 56\% of patients (17). A survey of physicians who referred patients with colorectal cancer for PET found that the PET findings contributed to management change in $62 \%$ of 


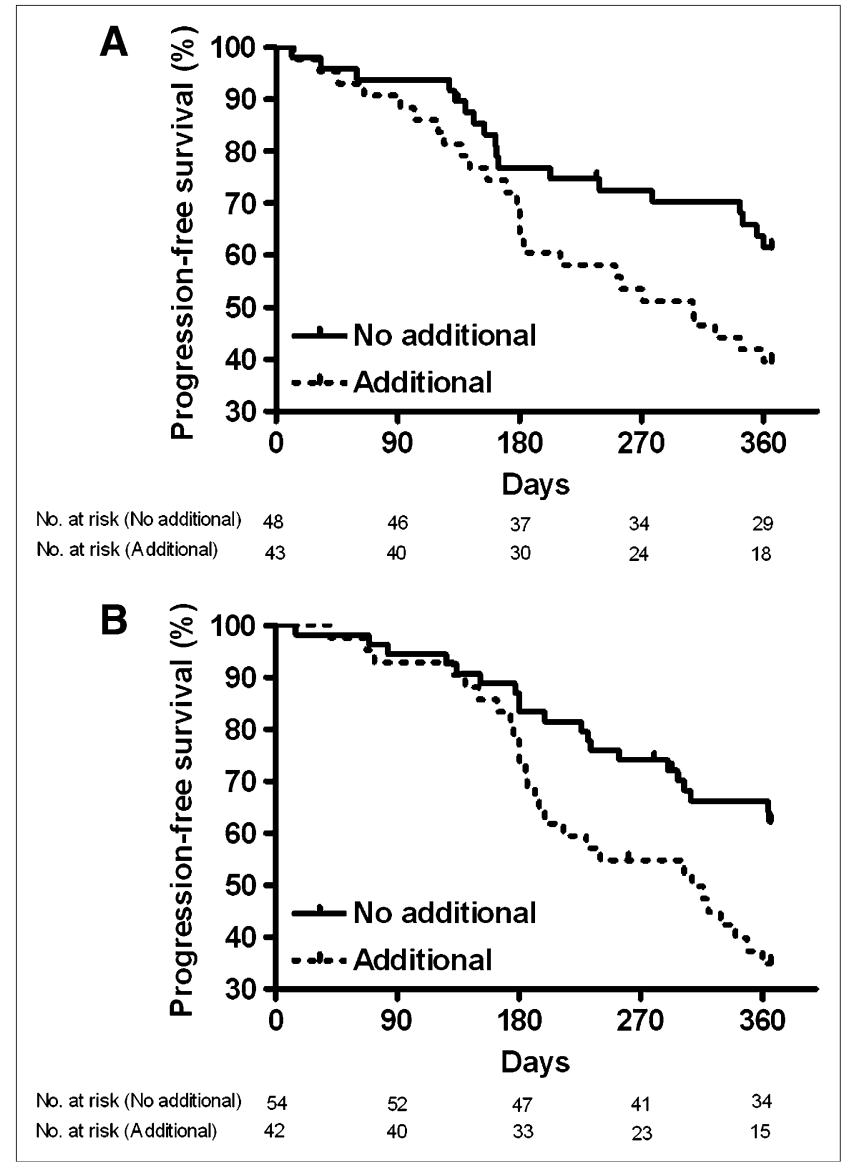

FIGURE 1. Kaplan-Meier analysis of progression-free survival for patients with additional lesions detected on PET vs. those with no additional lesions found on PET. Significant differences were found for group $\mathrm{A}(P=0.04)(\mathrm{A})$ and group $\mathrm{B}$ patients $(P=0.01)(\mathrm{B})$.

patients (23). This compares with the $65.6 \%$ of patients in group A and $49.0 \%$ in group B who had management change in our study. Our study represents the largest prospective study of PET conducted to date in patients with recurrent colorectal cancer.

PET detected additional sites of disease in $48.4 \%$ of group A patients and $43.9 \%$ of group B patients; a similar percentage of patients had lesions seen in pre-PET evaluation but not detected by PET. The majority of lesions detected by PET were categorized as consistent with malignancy. The superior ability of PET to accurately identify malignant lesions was confirmed by follow-up analysis. These results are consistent with data previously reported (18-20) and may underestimate the specificity of PET, as CT was used as the baseline for comparison in our study.

For patients with a residual structural lesion suggestive of recurrent tumor (group A), $29.0 \%$ of patients also had a change in intent of treatment (curative to palliative or palliative to curative) on the basis of PET results. The methodology used to obtain information on management plans was carefully designed to minimize bias for PET in the analysis of intent to treat and post-PET decision making.

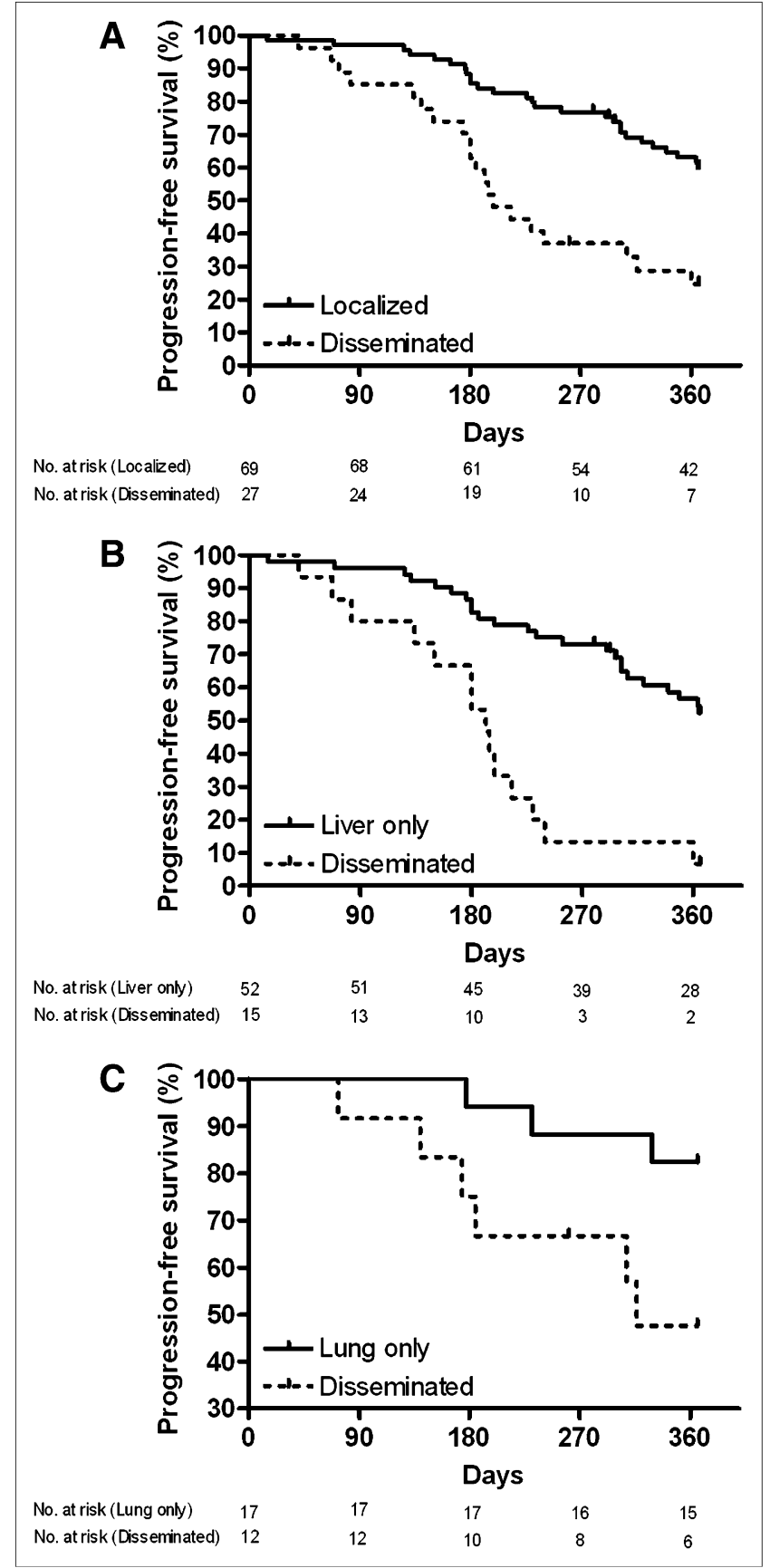

FIGURE 2. Kaplan-Meier analysis of progression-free survival for patients in group B with disease localized to either liver or lung on PET vs. those with disease in 2 or more organs (disseminated) $(P=0.0001)(\mathrm{A})$, those with disease localized to liver vs. those with liver and extrahepatic disease $(P<0.0001)$ $(B)$, and those with disease localized to lungs vs. those with lung and extrapulmonary disease $(P=0.04)(\mathrm{C})$.

Similar results were obtained for patients with pulmonary or hepatic metastases that were potentially resectable as determined by conventional imaging (group B): $23.5 \%$ of patients had a change in intent of treatment as a result of their PET scan. The slightly smaller number of patients who had change in intent post-PET in group B, compared with 


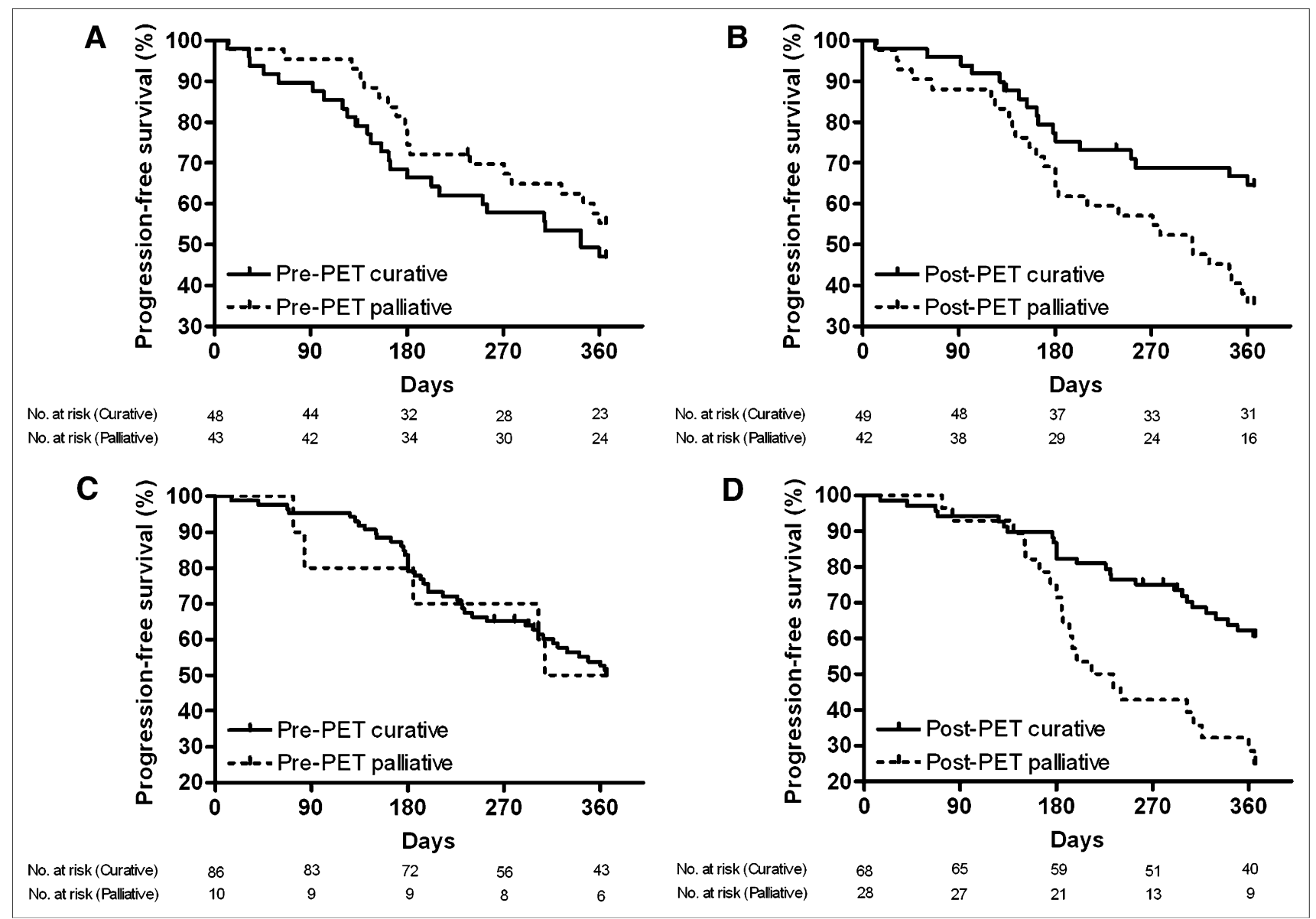

FIGURE 3. Kaplan-Meier analysis of progression-free survival for patients classified as curative or palliative for group A patients pre-PET $(P=0.32)(\mathrm{A})$, group A patients post-PET $(P=0.01)(\mathrm{B})$, group B patients pre-PET $(P=0.92)(\mathrm{C})$, and group B patients post-PET $(P<0.001)(D)$.

group A, may be because of the higher number of curativeintent patients in group B $(89.8 \%$ vs. $52.7 \%)$ pre-PET and the higher number of patients in this group for whom surgery was initially planned.

Clinical outcome at 12 mo was assessed by comparing the progression-free survival of patients grouped by various criteria pre-PET and post-PET. To our knowledge, there has not been a similar prospective assessment for a patient cohort of this size reported previously. These data show the value of PET in the stratification of patients into curative or palliative and surgical or nonsurgical groups. Patients who had additional lesions found on PET, compared with conventional imaging, had a poorer prognosis. Patients in group $\mathrm{B}$ with disease localized to the liver or lungs on PET had a better prognosis than did those with more disseminated disease. These data clearly show the powerful prognostic ability of PET to accurately stratify patients who are thought to have localized disease on conventional imaging. It is also possible, although unlikely, that some of the prognostic impact was because of changes in treatment based on the PET result.

There are some limitations to our study. Treating physicians were asked to indicate their planned management without PET, which may not always have been the actual management that occurred in the absence of PET. Patients were generally referred from outside institutions to the PET centers; therefore, prognostic factors such as the time between initial diagnosis and tumor recurrence could not always be recorded, and multivariate analyses including the PET findings were not possible. For similar reasons, it was also not possible to completely standardize pre-PET conventional imaging. However, these features reflect realworld clinical practice and do not detract from the clinical importance of the results that we report.

\section{CONCLUSION}

These data represent the largest prospective study yet reported that examines the impact of PET on patient management in recurrent colorectal cancer and demonstrates the impact of PET on patient management and outcomes.

\section{ACKNOWLEDGMENTS}

We acknowledge the Australian Government Department of Health and Ageing for funding and the Australian and New Zealand Association of Physicians in Nuclear Medicine for managing the PET Data Collection Project. We also thank 
Melinda Gibson, Debbie Lennon, and Anne-Maree Kerley for their contribution to data collection; Dr. Victor Kalff for his insightful comments; and the staff of the PET centers involved in the study.

\section{REFERENCES}

1. Australian Institute of Health and Welfare (AIHW) and Australasian Association of Cancer Registries (AACR). Cancer in Australia 2001. Canberra, Australia: AIHW; 2004. Cancer Series no. 28.

2. American Cancer Society. Cancer Facts and Figures 2006. Atlanta, GA: American Cancer Society; 2006.

3. Goldberg RM. Intensive surveillance after stage II or III colorectal cancer: is it worth it? J Clin Oncol. 2006;24:330-331.

4. Tepper JE, O'Connell M, Hollis D, et al. Analysis of surgical salvage after failure of primary therapy in rectal cancer: results from Intergroup Study 0114. J Clin Oncol. 2003;21:3623-3628.

5. Goldberg RM, Fleming TR, Tangen CM, et al. Surgery for recurrent colon cancer: strategies for identifying resectable recurrence and success rates after resection. Eastern Cooperative Oncology Group, the North Central Cancer Treatment Group, and the Southwest Oncology Group. Ann Intern Med. 1998;129:27-35.

6. Fong Y, Fortner J, Sun RL, et al. Clinical score for predicting recurrence after hepatic resection for metastatic colorectal cancer: analysis of 1001 consecutive cases. Ann Surg. 1999;230:309-318.

7. Nordlinger B, Guiguet M, Vaillant JC, et al. Surgical resection of colorectal carcinoma metastases to the liver: a prognostic scoring system to improve case selection, based on 1568 patients. Association Francaise de Chirurgie. Cancer. 1996;77:1254-1262.

8. Poston GJ, Adam R, Alberts S, et al. OncoSurge: a strategy for improving resectability with curative intent in metastatic colorectal cancer. J Clin Oncol. 2005;23:7125-7134.

9. Iizasa T, Suzuki M, Yoshida S, et al. Prediction of prognosis and surgical indications for pulmonary metastasectomy from colorectal cancer. Ann Thorac Surg. 2006;82:254-260.

10. Scott AM. Current status of positron emission tomography in oncology. Int Med J. 2001;31:27-36.
11. Huebner RH, Park KC, Shepherd JE, et al. A meta-analysis of the literature for whole-body FDG PET detection of recurrent colorectal cancer. $\mathrm{J} \mathrm{Nucl} \mathrm{Med}$. 2000;41:1177-1189.

12. Lai DT, Fulham M, Stephen MS, et al. The role of whole-body positron emission tomography with $\left[{ }^{18} \mathrm{~F}\right]$ fluorodeoxyglucose in identifying operable colorectal cancer metastases to the liver. Arch Surg. 1996;131:703-707.

13. Ogunbiyi OA, Flanagan FL, Dehdashti F, et al. Detection of recurrent and metastatic colorectal cancer: comparison of positron emission tomography and computed tomography. Ann Surg Oncol. 1997;4:613-620.

14. Flamen P, Stroobants S, Van Cutsem E, et al. Additional value of whole-body positron emission tomography with fluorine-18-2-fluoro-2-deoxy-D-glucose in recurrent colorectal cancer. J Clin Oncol. 1999;17:894-901.

15. Akhurst T, Larson SM. Positron emission tomography imaging of colorectal cancer. Semin Oncol. 1999;26:577-583.

16. Schoder H, Larson SM. PET/CT in oncology: integration into clinical management of lymphoma, melanoma and gastrointestinal malignancies. J Nucl Med. 2004;45(suppl):72S-81S.

17. Kalff V, Hicks RJ, Ware RE, et al. The clinical impact of ${ }^{18} \mathrm{~F}$-FDG PET in patients with suspected or confirmed recurrence of colorectal cancer: a prospective study. J Nucl Med. 2002;43:492-499.

18. Bipat S, Van Leeuwen MS, Comans EF, et al. Colorectal liver metastases: CT, MR imaging, and PET for diagnosis-meta-analysis. Radiology. 2005;237:123-131.

19. Wiering B, Krabbe PF, Jager GJ, et al. The impact of fluor-18-deoxyglucosepositron emission tomography in the management of colorectal liver metastases. Cancer. 2005;104:2658-2670.

20. Ruers TJ, Langenhoff BS, Neeleman N, et al. Value of positron emission tomography with [F-18]fluorodeoxyglucose in patients with colorectal liver metastases: a prospective study. J Clin Oncol. 2002;20:388-395.

21. Fernandez FG, Drebin JA, Linehan DC, et al. Five-year survival after resection of hepatic metastases from colorectal cancer in patients screened by positron emission tomography with F-18 fluorodeoxyglucose (FDG-PET). Ann Surg. 2004;240:438-447.

22. Hillner BE, Siegel BA, Liu D, et al. Impact of positron emission tomography/ computed tomography and positron emission tomography (PET) alone on expected management of patients with cancer: initial results from the national oncologic PET registry. J Clin Oncol. 2008;26:2155-2161.

23. Meta J, Seltzer M, Schiepers C, et al. Impact of ${ }^{18}$ F-FDG PET on managing patients with colorectal cancer: the referring physician's perspective. $J$ Nucl Med. 2001;42:586-590. 